\title{
Organização da multimídia em ebook interativo infantil
}

\author{
Multimedia organization of children's interactive ebook
}

\author{
- Deglaucy Jorge Teixeira \\ UFSC, Florianópolis-SC \\ Deglaucyjorge@gmail.com \\ - Berenice S. Gonçalves \\ UFSC, Florianópolis-SC \\ bereni.gon@gmail.com
}

\author{
Milton Luiz Horn Vieira \\ UFSC, Florianópolis-SC \\ mlvieira@mbox1.ufsc.br
}

\begin{abstract}
For the purchase of children's traditional books, the Brazilian government, through the Fundo Nacional de Desenvolvimento na Educação (FNDE) uses as one of the quality criteria, the balance between text and image. It is also important to have organizational criteria of media into interactive digital books. Through bibliographical and exploratory study, with a systematic review as support, this research aimed to investigate the organizational forms of static and dynamic media on a children's interactive ebook. The results showed that story can operate as a structural factor, following the organization in screens based models or based on sync.
\end{abstract}

Keywords: Digital Multimedia, Media, Children's Interactive Ebook, Children's Book App

\section{Introduction}

Contar histórias por meio de imagens, tal como as pinturas rupestres, deu início as atuais possibilidades de unir ilustração com grupos de palavras em uma composição híbrida para transmitir sentido em conteúdos de livros ilustrados infantis.

$\mathrm{Na}$ perspectiva das novas tecnologias da informação e comunicação (TICs), as histórias presentes nos livros infantis ilustrados ganharam outras mídias para compor sua narrativa, como som e animação, fortalecendo assim, o seu caráter multimídia em ambiente digital com chances de interatividade. $\mathrm{O}$ que antes era impresso e encadernado em papel, agora tornou-se um livro eletrônico - os ebooks interativos infantis.

Este novo suporte de leitura trouxe algumas mudanças às políticas públicas brasileiras de fomento a leitura. Estima-se que em 2017 todos os livros didáticos distribuídos pelo governo estejam disponíveis em formatos digitais. Sendo que desde de 2013, com a distribuição de tablets para os professores da rede pública, o Brasil vem incentivando, de forma gradual, o uso das tecnologias digitais nas escolas (TOKARNIA, 2014).

Atualmente, a organização do conteúdo é um dos aspectos de avaliação de qualidade para seleção de obras impressa para criança. No edital do Plano Nacional Biblioteca da Escola (PNBE), proposto pelo Fundo Nacional de Desenvolvimento na Educação (FNDE) para aquisição de obras de literatura destinadas às escolas públicas em 2015, além dos aspectos de legibilidade, exige que o projeto gráfico-editorial equilibre o texto às ilustrações e a outras intervenções gráficas que conduzam o leitor para dentro e para fora do texto principal (BRASIL, 2014).

No ebook interativo de histórias infantis a necessidade de organizar as mídias de forma significativa torna-se mais complexa, pois além de texto e imagem, este suporte pode envolver animação e som.

Diante deste cenário, é importante que, além dos critérios de organização das mídias para obras impressas, seja sugerido formas significativas para integrar as mídias em livros digitais interativos. Possibilitando assim, criar critérios de qualidades em livros interativos, tanto para editais governamentais quanto para determinar atributos necessários do design e produção destes ebooks infantis.

Em recente pesquisa de revisão sistemática sobre conhecimentos necessários para integrar a multimídia e a interatividade em narrativa digital infantil, Teixeira et al (2014), destacou a possibilidade de estudar a multimídia em ebook interativo infantil a partir de conceitos tradicionais que relacionam texto e imagem em livros ilustrados.

O objetivo desta pesquisa foi explorar as especificidades e os possíveis padrões de organizações dos elementos da multimídia, utilizando, portanto, esses conceitos tradicionais para organização de imagem e texto em narrativas para criança a partir de duas possibilidades, a saber:

Organização de texto e imagem em livros infantis 
ilustrados: Associação, Dissociação e Conjunção(LINDEN, 2011);

Organização de texto e imagem em arte sequencial: específicas de palavras, específicas de imagem, duo-específicos, combinação aditiva, combinação paralela e montagem (MCCLOUD, 1995).

Desta maneira, alinhou-se esses conceitos com os tipos de organização da multimídia em ambiente digital: combinação de mídia estática com mídia dinâmica (RIBEIRO, 2012; CHAPMAN, 2000; e VAUGHAN, 2014).

Afim de explorar as potencialidades disponíveis da tecnologia digital é necessário conhecer as características específicas dos tipos de mídias e adequar as combinações de informação visual e auditiva às mensagens que se deseja transmitir (RIBEIRO, 2012).

Prosseguindo com a pesquisa de Teixeira et al (2014), fez-se um levantamento bibliográfico sobre ebook interativo tomando como enfoque, as mídias utilizadas para contar história. Isto posto, junto ao estudo dos elementos de multimídia, analisou-se uma obra selecionada pelo edital de aquisição governamental, ou seja, com crivo de qualidade no que tange a composição da mídias - texto e imagem. Elencouse a obra É assim, da autoria Paloma Valdivia, em seus dois formatos, impresso e digital (ebook).

O formato impresso dessa obra, publicado no Brasil pela editor SM, foi selecionado pelo Programa Nacional Biblioteca na Escola do Ministério da Educação (PNBE - MEC) em 2012 (BRASIL, 2011) e distribuído gratuitamente para as escolas públicas de ensino básico no Brasil.

A mesma obra em formato de ebook interativo, denominado Es así, foi publicada pela editora mexicana Fondo de Cultura Económica e distribuído pela Apple Store em versão bilíngue inglês e espanhol.

\section{Livro infantil ilustrado}

Segundo Powers (2008), desde o século XVIII, há diversificação de projetos gráficos de livros para o público infantil, com variações de tamanho, cores, ilustrações, suportes e tecnologia de impressão.

Os tipos de livros destinados ao público infantil, segundo Linden (2011), podem ser classificados de acordo com sua estrutura e a relação imagem e texto em seu conteúdo.

Em um livro ilustrado - obra narrativa em que a imagem é espacialmente predominante ou não existe texto - todos os elementos devem estar totalmente integrados. A tipografia, as ilustrações e todos os elementos visuais devem ser devidamente concebidos em uma unidade e todas suas características são fundamentais para compreensão da história (SIPE, 2001).

Para Salisbury e Styles (2013), no design de livro infantil ilustrado, o texto e a imagem possuem a mesma importância narrativa e, na maioria dos casos, nenhum deles faz sentido quando usado separadamente. Por isso existem critérios para organização de texto e imagem em histórias ilustradas, tanto em livro infantil quanto em obras de arte sequencial.
Estes critérios favorecem significativamente para que as mídias, texto e imagem, sejam organizadas de forma efetiva, contribuindo assim, para o ato de contar história.

Para Serafini (2014), Bader, em seu livro American Picturebooks from Noah's Ark to the Beats de 1976 , conseguiu definir o livro infantil ilustrado abrangendo todos os seus aspectos. De acordo com Barder, o livro infantil ilustrado é um design completo - texto e ilustrações. Um produto que atua como documento social, cultural e histórico que traz experiências para as crianças. Em sua forma artística, o livro infantil ilustrado depende da interdependência da imagem com a palavra, simultaneamente exibidas em duas faces dramatizada com a virada de página (BARDER apud SERAFINI, 2014).

Por meio do livro ilustrado a criança aprende a ler texto e imagem. Estas mídias operam de uma maneira particular, onde nem sempre a mesma historia é contada, podendo a imagem contrastar com o texto. Quando uma obra se apresenta desta forma, isso é denominado contraponto - usado por autores e ilustradores para aumentar a profundidade da narrativa, fazendo com que o leitor tenha um envolvimento ativo ao utilizar sua imaginação para compreender a relação do texto com a imagem (SARGEANT, 2013).

\subsection{Mídias em livro ilustrado infantil}

Livro de imagens impressos podem incorporar outras mídias além de texto e imagem. Por exemplo: livro com dispositivos sonoros que são ativados ao abri-lo ou por botões e livros com esculturas em pop-up que se abrem entre as páginas. Da mesma forma os books apps integram imagens animadas, sons e texto.

Osjogos, vistoscomobrincadeiras dentrodeuma estrutura rígida, ou mesmo quebra-cabeças são frequentemente encontrados nos livros infantis impressos e nos formatos digitais.

Embora esses elementos lúdicos possam ser um convite para o jogo, eles não são considerados formalmente como jogos. De acordo com Juul (2003) o jogo é um sistema formal baseado em regras com resultados variáveis e quantificáveis, com possibilidade do jogador influenciar o resultado do jogo mediante seus esforços, tornando-o cada vez mais apegado ao resultado.

Ao considerar os livros ilustrados como uma mídia de arte sequencial, é possível relacionar a organização dos seus elementos com as cinco categorias para combinar texto escrito e imagem (MCCLOUD, 1995), a saber:

a) Específicas de palavras, onde as imagens pouco acrescentam ao texto;

b) Específicas de imagem, onde o texto representa uma sequência visualmente falada;

c) Duo-específicos, onde texto e imagem transmitem a mesma mensagem;

d) Combinação aditiva, onde o texto amplia ou elabora sobre uma imagem;

e) Combinação paralela, onde texto e imagem seguem 
cursos diferentes;

f) Montagem, onde o texto é parte integrante da imagem; e

g) Interdependente, onde texto e imagem não podem transmitir a mensagem separadamente.

Em estudos dirigidos ao livro ilustrado infantil, Linden (2011) resumiu os modelos teóricos que relacionam texto e imagem em três maneiras, a saber:

a) Relação de redundância, onde o conteúdo significativo de texto e imagem são equivalentes. Neste caso existe uma congruência sem dependência um do outro no discurso, ou seja, a narrativa pode ser sustentada apenas com uma das mídias, sem necessidade da outra para compreensão global da história, neste caso não existe contraponto;

b) Relação de colaboração, onde a articulação das mídias constroem um sentido único, combinando força e fraqueza de cada uma. Neste caso o significado emerge da relação do texto com a imagem.

c) Relação de disjunção, onde é possível assumir narrações paralelas, ou seja, sem ponto de convergência, não é possível definir um único significado, deixando o campo de interpretações em aberto para o leitor.

No contexto dos novos formatos dos livro ilustrados infantis, o ambiente digital possibilita a integração de outras mídias além do texto e imagem para compor a narrativa, tais como som e animação.

\subsection{Livro digital interativo infantil}

Deacordocom Flatschart (2014), olivrodigital(livroeletrônico, e-book, eBook, ebook, ou e-edition) é uma publicação em formato digital, que pode ser lida em dispositivos computacionais, podendo conter textos escritos, imagens e outros recursos, bem como multimídia e interatividade.

O book app, ou seja, o livro digital interativo em formato aplicativo (software), permite maior flexibilidade, onde o leitor pode interagir com links, sair de um texto, mudar o idioma, navegar de forma não linear entre objetos, personagens, sumários visuais, objetos lúdicos, animações, som e vídeos.

Atualmente, as potencialidades específicas dos suportes para o livro digital trazem mudanças também no processo de organização de seus elementos constitutivos, uma vez que os dispositivos eletrônicos apropriados para leitura dos ebooks permitem uma série de configurações e interferências na apresentação do conteúdo. Neste caso, o design de um livro digital envolve mais que o planejamento do layout de página, com estudo da diagramação, grid, cor, tipografia etc., como é feito para livro tradicional.

O formato digital interativo é indicado para tablets ou smartphones, que permitem interação com câmera e experiências táteis, como: telas multitouch, sensor de localização (GPS), sensor de orientação (bússola), sensor de iluminação (ajustes de brilho da tela), sensores de movimento com o acelerômetro etc. Além da multimídia e dos elementos interativos, o uso destes recursos podem afetar diretamente os elementos narrativos em uma história.
De acordo com Stichnothe (2014), no momento presente é importante que se faça um estudo crítico e profundo na perspectiva de uma literatura emergente, que pode ser avaliada do ponto de vista das narrativas digitais interativas e da teoria das mídias. Considerando, principalmente, a forma como estes livros aplicativos trabalham a narrativa no âmbito da multimídia digital, com representações visuais, verbais e sonoras. Neste estudo, foi considerado o uso das mídias em seus aspectos multimídiaticos.

\section{Multimídia digital}

A integração de formas variadas de informações na busca de um sentido é um processo natural do ser humano, pois é possível apreender diferentes informações, simultaneamente, por meio dos sentidos.

O termo multimídia refere-se ao conjunto diferenciado destas informações. Etimologicamente, segundo Ribeiro (2012), o termo multimídia é a junção do prefixo "multi" com a raiz "mídia". "Multi" define o que é numeroso, enquanto mídia remete ao plural do termo latino medium, que significa meio ou intermediário. Desta forma a palavra multimídia designa múltiplos intermediários ou múltiplos meios como forma de comunicação para transmitir uma mensagem.

O conceito de multimídia ainda pode variar de acordo com seu contexto, tais como um setor de mercado, um software (aplicativo), um produto que suporta um aplicativo multimídia, um serviço para apresentação de conteúdo, um conjunto de áreas tecnológicas, placa (hardware), plataforma (componentes específicos em um hardware), dispositivo de armazenamento e rede de comunicação (RIBEIRO, 2012).

Para Sargeant (2013), no estudo do livro ilustrado infantil tradicional, multimídia refere-se a combinação a partir de duas mídias, tal comotextoeimagem, independentedesua materialidade.

No entanto, tratando da organização das mídias, é possível definir a multimídia como uma combinação dos tipos de mídias, ou seja, texto, imagem, som, animação e vídeo, apresentada ao usuário por um meio digital (VAUGHAN, 2014).

É importante destacar que o ambiente digital permite o controle dos tipos de mídias ou conteúdos apresentados ao usuário. Especificamente esta situação refere-se a multimídia interativa, também definida como hipermídia (VAUGHAN, 2014).

No âmbito deste estudo foi explorado o conceito de multimídia como sistema de informação manipulado, digitalizado e controlado por computador, ou seja, a multimídia digital, com foco na organização dos tipos de mídias.

\subsection{Tipos mídias}

As informações audiovisuais podem ser combinadas para difundir um conteúdo em vários contextos, tais como um programa na TV, uma peça de teatro, um game ou um filme no cinema. Os sistema de aplicativos multimídia, como um software, podem combinar diferentes mídias, tais como: texto, imagens, vídeos, animações e áudio. Explicados a seguir:

a) Texto: considerado uma mídia dominante para 
apresentação da informação, tanto de forma convencional como digitalizado. Na forma digital, o texto pode se apresentar como texto plano (plain text), comumente utilizado pelos processadores de texto e o texto rico (rich text), muito utilizado em livros, jornais e revistas, geralmente criado e organizado por programas de editoração eletrônica;

b) Imagens: esta categoria abrange fotografias ou ilustrações (imagens do tipo bitmap) e gráficos vetoriais;

c) Vídeos: os vídeos são documentos audiovisuais que podem ser criados a partir de uma câmera de vídeo digital ou digitalizado a partir de uma captura analógica. Ou ainda, gerados diretamente no computador por meio de software de edição de vídeo;

d) Animação: esta categoria, assim como os vídeos, são classificadas também como imagem em movimento e, especificamente na animação, estas imagens são geradas sinteticamente por computadores;

e) Áudio: assim como os vídeos, podem ser proveniente de sons digitalizados a partir de fontes sonoras ou sintetizados diretamente no computador.

Geralmente determinados tipos de mídias são utilizados em documentos específicos ou em apresentações convencionais (ver Quadro 1).

\begin{tabular}{|c|c|c|}
\hline $\begin{array}{c}\text { Tipos de mídias } \\
\text { digitais }\end{array}$ & $\begin{array}{l}\text { Correspondente } \\
\text { utilizado em } \\
\text { documentos } \\
\text { analógicos }\end{array}$ & $\begin{array}{c}\text { Exemplos de } \\
\text { documentos ou } \\
\text { apresentações } \\
\text { convencionais }\end{array}$ \\
\hline Imagem & Fotografia & \multirow{2}{*}{$\begin{array}{c}\text { Revistas, jornais e } \\
\text { livros }\end{array}$} \\
\hline Gráficos & $\begin{array}{l}\text { Desenhos / } \\
\text { esquemas }\end{array}$ & \\
\hline Áudio (digital) & Áudio (analógico) & \multirow{2}{*}{$\begin{array}{c}\text { Programas de TV, } \\
\text { clips de áudio e } \\
\text { vídeo, cinema } \\
\text { e produções } \\
\text { audiovisuais }\end{array}$} \\
\hline Vídeo (digital) & Vídeo(analógico) & \\
\hline Animação & Desenho animado & $\begin{array}{l}\text { Cinema de } \\
\text { animação }\end{array}$ \\
\hline
\end{tabular}

Quadro 1: Tipos de mídias digitais e seus correspondentes analógicos utilizados em documentos convencionais. Adaptado pelo autor com base no esquema de Ribeiro (2012).

Os tipos de mídias, também denominadas informações multimídias, podem ser classificadas de acordo com sua natureza (Quadro 2) em mídias estáticas e mídias dinâmicas (CHAPMAN \& CHAPMAN, 2000 e RIBEIRO, 2012).

Os tipos de mídias estáticas são constituídas de informações que independem do tempo. Seu significado está diretamente ligado a localização e variação das suas dimensões espaciais, tais como, tamanho, formato, parágrafo de texto, modelos gráficos ou conjunto de pixels.

Ao contrário, os tipos de mídias dinâmicas incluem informações que exigem reprodução contínua, onde o tempo faz parte do próprio conteúdo. Neste caso, o significado pode se alterado se a sequencia dos elementos que constitui o conteúdo dinâmico for modificada. São as sucessões de imagens ou de gráficos que surgem em uma tela que dão a impressão de movimento. Daí a designação destes tipos de mídias como imagens em movimento para os vídeos digitais e gráficos em movimento de animações (Ribeiro, 2012).

De acordo com o quadro 2 é possível perceber a correlação entre as mídias estáticas e dinâmicas, onde o correspondente dinâmico da imagem é o vídeo e do gráfico é a animação. Apesar dos tipos de mídias texto e áudio não possuírem correspondentes é possível considerar a narração falada como um tipo especial de áudio que se relaciona dinamicamente com a mídia texto.

\begin{tabular}{|c|c|}
\hline Mídias estáticas & Mídias dinâmicas \\
\hline Imagem & $\begin{array}{c}\text { Vídeo (imagem em movi- } \\
\text { mento) }\end{array}$ \\
\hline- & Áudio \\
\hline Texto & - \\
\hline Gráfico & Animação \\
\hline
\end{tabular}

Quadro 2: Classificação dos tipos de informação multimídia. Adaptado pelo autor com base no esquema de Ribeiro (2012).

Em uma verdadeira apresentação multimídia deve-se atentar para os tipos de combinações permitidas. Segundo Ribeiro (2012), geralmente a combinação das mídias devem ocorrer com pelo menos um tipo de mídia estática com um tipo de mídia dinâmica. Desta maneira, um documento que inclua a organização de texto e imagem, mesmo em ambiente digital, não é considerado como um documento multimídia ou sistema multimídia.

Nessas condições, Ribeiro (2012) definiu cinco características principais associadas aos sistemas multimídia, a saber:

1. Formato digital com mídias independentes;

2. Obrigatoriamente, combinação de pelo menos uma mídia estática e uma mídia dinâmica;

3. Os tipos de mídias são controlados por computadores;

4. Os tipos de mídias funcionam de forma integrada. Apresentados via interface unificada e manipulada por meio de um único programa (aplicativo/software);

5. Interface que pode permitir interatividade.

Diante destas características, os aplicativos multimídias devem compor um espaço de informação funcional e significativo a fim de reduzir a sobrecarga cognitiva recebida pelo usuário, facilitando o acesso ao conteúdo, a compreensão da informação e minimizando a complexidade do espaço de informação para facilitar a navegação do usuário. Sendo assim, é necessário uma combinação dos tipos de mídias espacialmente e temporalmente estruturados de forma lógica em relação ao conteúdo. 


\subsection{Organização da multimídia}

A combinação das mídias em um documento está diretamente relacionada ao conceito de autoria multimídia. Este conceito refere-seaoprocessodeorganizaçãodasmídiaseinteratividade por meio de um software específico, criando ligações entre os conteúdos e entre as unidades de apresentação da informação (ligação entre telas ou páginas). Possibilitando, inclusive, a criação de um espaço informacional navegável.

De acordo com Ribeiro (2012) existem dois modelos fundamentais para organizar a multimídia, a saber: o modelo baseado em organização no conteúdo na tela e o modelo baseado na sincronia temporal de conteúdo, comum em composição de filmes de cinema.

O modelo baseado em telas é o que mais se aproxima da disposição espacial utilizada em vários conteúdos tradicionais, tal como a organização de texto e imagem em livros infantis impressos. Neste caso, acrescenta-se os tipos de mídias dinâmicas junto às mídias estáticas em uma área predeterminada.

Aos conteúdos dinâmicos é possível acrescentar elementos interativos capazes de acionar ou interromper ações, reproduções e hiperlinks. Os aplicativos de multimídia interativa resultantes deste processo de concepção em telas são designados com hipermídia. Geralmente este aplicativos não construídos em composição espacial bidimensional utilizando elementos adicionais, tais como botões, ícones e scripts para lidar com as mídias dinâmicas e a interatividade. Entretanto, existem aplicativos desenvolvidos com base espacial tridimensional frequentemente utilizados em jogos e aplicativos de realidade virtual (Ribeiro, 2012).

O modelo baseadoem sincronia doconteúdoé semelhante a produção de filmes ou slides, onde os diversos elementos são organizados em uma linha temporal. Além disso, esta forma de organização permite sincronizar elementos em paralelo, apresentando-os simultaneamente, por exemplo, um áudio de narração sobre uma imagem ao fundo e destaque de palavras em um conjunto de parágrafos de texto. Acrescentando ainda, elementos interativos, muito comum em livro digital interativo infantil.

É importante destacar que ambos os modelos permitem a organização espacial e temporal, distinguindo-se apenas quanto às bases projetuais, onde o modelo baseado em tela tem como base a organização espacial e o modelo baseado em sincronização tem como base a organização temporal.

\section{Procedimentos metodológicos}

Inicialmente, selecionou-se uma obra de literatura infantil com crivo de qualidade do Plano Nacional Biblioteca da Escola (PNBE - PNBE). Este estudo focou na organização das mídias na versão ebook interativo acessado em um tablet, junto a organização do texto e imagem na versão impressa.

Elencou-se, portanto, a obra É assim da autoria Paloma Valdivia em suas versões impressa e digital (ver Figura 1). Segundo Creswell (2010), o fato de indicar intencionalmente os elementos para o estudo proposto é uma das características da abordagem qualitativa, desta forma, estes elementos contribuirão para o entendimento do problema e da questão de pesquisa.
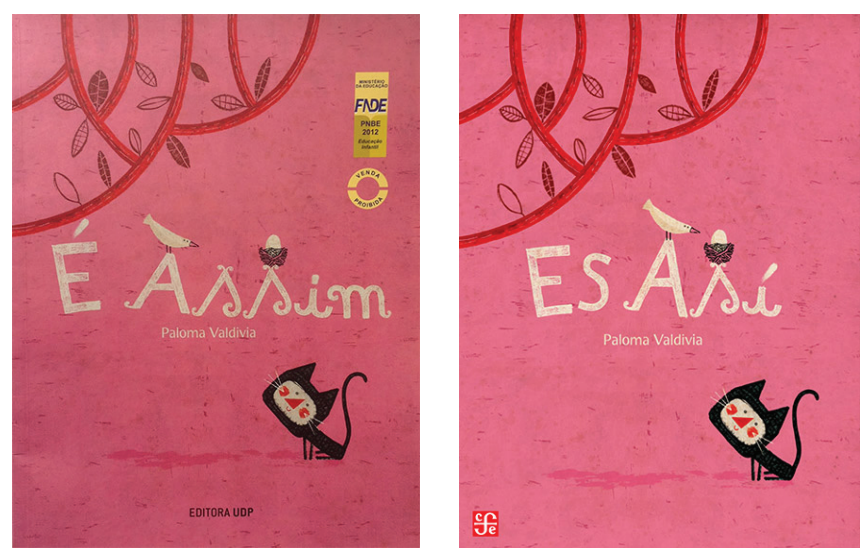

Figura 1: Obra selecionada para análise: versão impressa e versão digital (ebook interativo). Imagens capturadas pelo autor.

Com base no estudo bibliográfica, utilizado como guia de investigação e fundamentação teórica, categorizou-se os critérios de organização das mídias, imagem e texto, em histórias infantis publicadas em livros impressos.

Em seguida classificou-se as especificidades das mídias e suas formas de organização em multimídia digital.

Por fim, fez se uma análise descritiva a partir das categorias de organização da multimídia no contexto da obra, apresentada em artefato impresso e digital. Para essa análise, foram selecionadas telas em que as mídias som e/ou animação acrescentam conteúdo significativo por meio de elementos que não estavam presentes na versão impressa. Estas telas, juntamente com as páginas correspondentes do livro impresso, foram representadas nesta pesquisa por meio de figuras, não para comparação, mas com fins ilustrativos dessa análise.

\section{Análises e Discussões}

A obra É assim conta a história do ciclo da vida, contrapondo situações de partida e de chegada, vida e morte em frases curtas e poéticas.

Foram elencada seis cenas, ou seja, três páginas duplas do livro impresso e seis telas do ebook interativo.

A primeira cena mostra vários personagens ilustrados com asas acompanhados do texto: "alguns já partiram...". Além da imagem e do texto, no ebook é possível e clicar nos personagens, acionando animação e falas e ouvir a voz do narrador ao som de um piano como tema musical. Com isso cada personagem diz "adeus", dramatizado em diferentes idiomas e, "batendo as asas", saem da tela (ver Figura 2). 
A segunda cena traz a imagem de uma panela de sopa com o texto: "O gato do vizinho, a tia Margarida, o peixe da sopa de ontem." No ebook interativo, além da imagem, do texto escrito e narrado e do tema musical, é possível clicar e acionar uma animação em que a sopa vai diminuído junto a uma fumaça, até findar em uma espinha de peixe, acompanhado por efeitos sonoros desta ação (ver Figura 2).
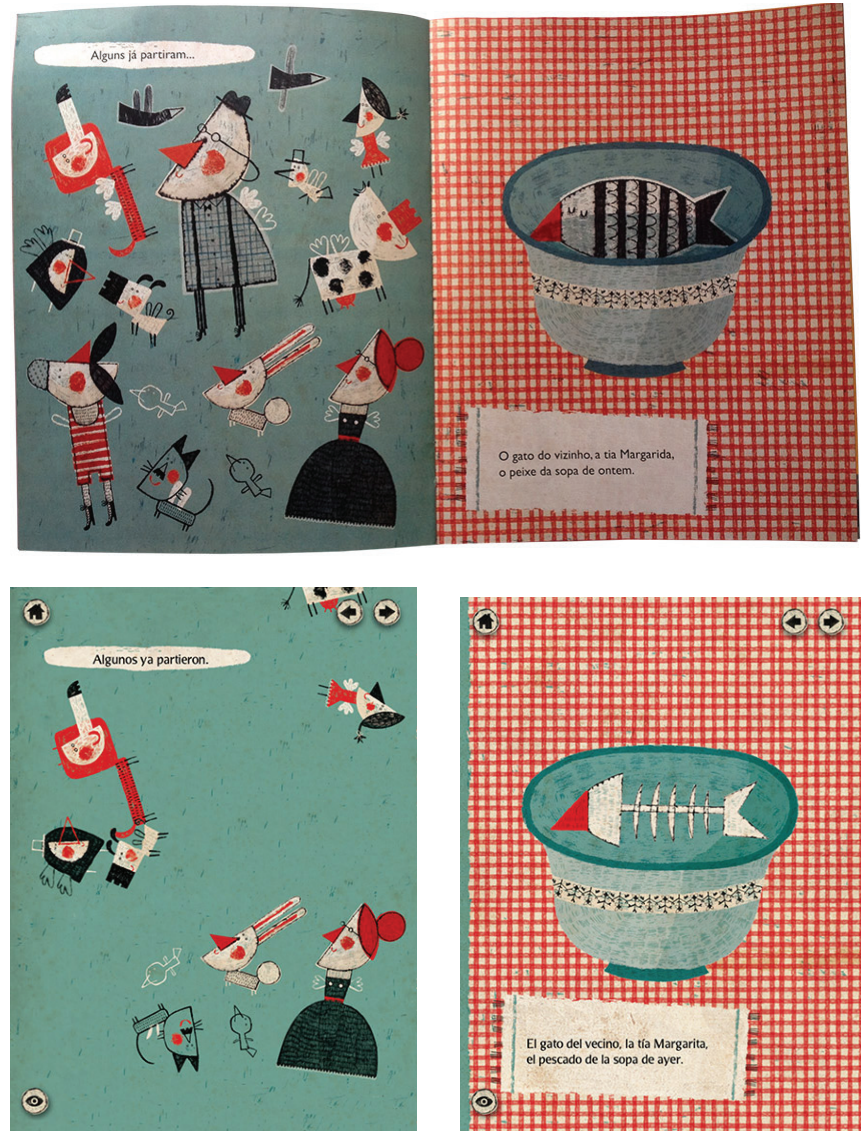

Figura 2: Cenas 1 e 2: versão impressa e versão digital (ebook interativo). Imagens capturadas pelo autor.

As cenas 3 e 4 compartilham o mesmo texto: "Outros chegaram. Uns foram desejados, outros vieram sem perguntar." No ebook as cenas podem ser acessadas ao arrastar o dedo na tela no sentido horizontal. O tema musical, as imagens, os texto escritos e narrados são comuns em todas as cenas na versão digital. Nessas duas cenas ainda é possível interagir com uma "lente" e descobrir o conteúdo de uma sacola de compras e clicar em cada elemento na barriga, acionando uma animação que os faz se deslocar para fora, acompanhada de efeitos sonoros.

A quinta cena traz o texto: "Nós, que aqui estamos, choramos pelos que partem." Nessa cena é possível acionar animação da chuva e raios e ainda ouvir efeitos sonoros de tempestade e o canto do passarinho.

A sexta cena apresenta o texto: "É bonito lembrar." Nessa cena existe uma animação da personagem central que vai
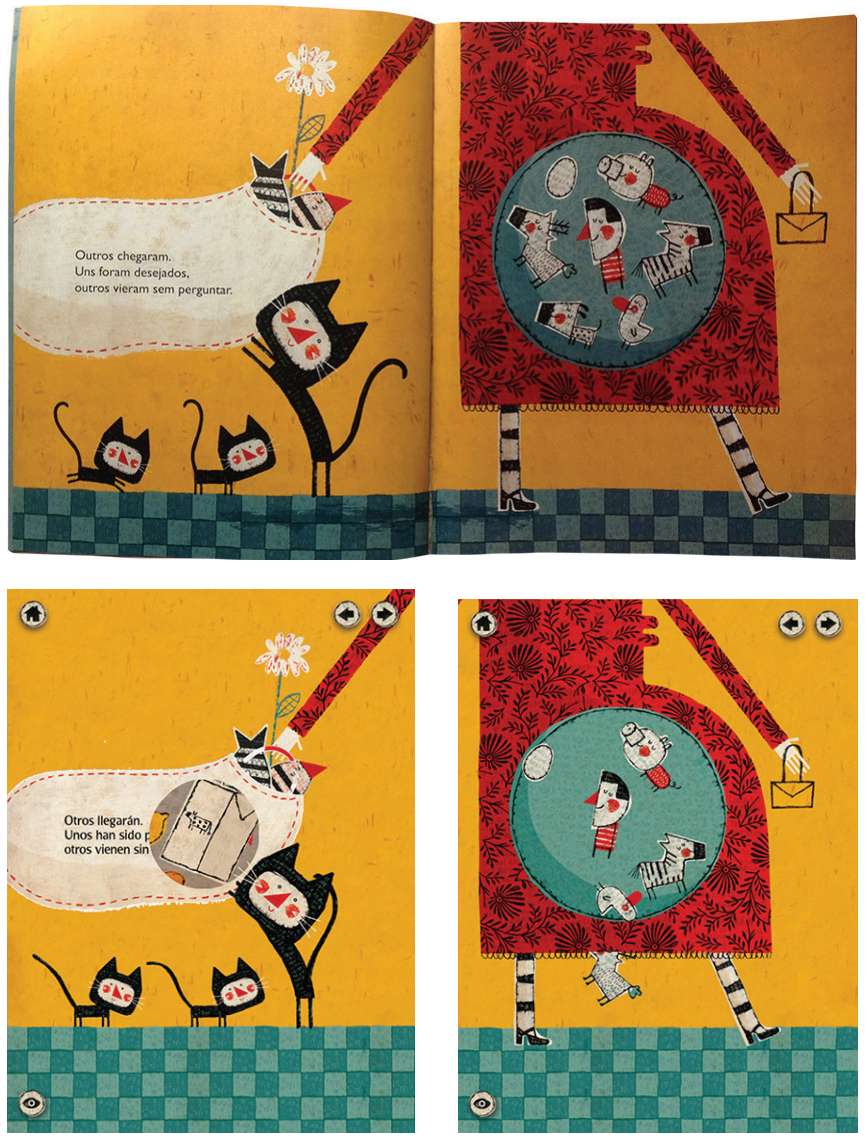

Figura 3: Cenas 3 e 4: versão impressa e versão digital (ebook interativo). Imagens capturadas pelo autor.

rodando com uma criança e ao clicar na tela surge objetos que é possível arrastá-los no cenário. Tudo isso acompanhado de tema musical e efeitos sonoros.

Nas cenas analisadas do ebook Es así as mídias dinâmicas integraram-se às mídias estáticas de forma colaborativa, contribuindo e ampliando o significado da obra em uma organização baseada em telas, priorizando a estrutura espacial e com projeto gráfico visualmente mais próxima do formato impresso.

No entanto, em uma multimídia também é possível organizar os tipos de mídias em modelo baseado em sincronia de conteúdo, semelhante a produção de filmes, tendo como base, a integração do conteúdo baseado no tempo. Sendo que ambos os modelos permitem a organização espacial e temporal, não sendo portanto, excludentes.

A partir da combinação de texto e imagem na versão impressa da obra analisada observou-se que em todas as cenas existe uma combinação aditiva, onde o significado de ambas as mídias se ampliam em uma relação de colaboração.

Esta organização prosseguiu na versão digital, com o alinhamento de uma mídia estática junto a uma ou duas mídias dinâmicas. Tal como a combinação do texto escrito com a narração e com o tema musical, ou mesmo a imagem estática com o tema musical ao fundo. 

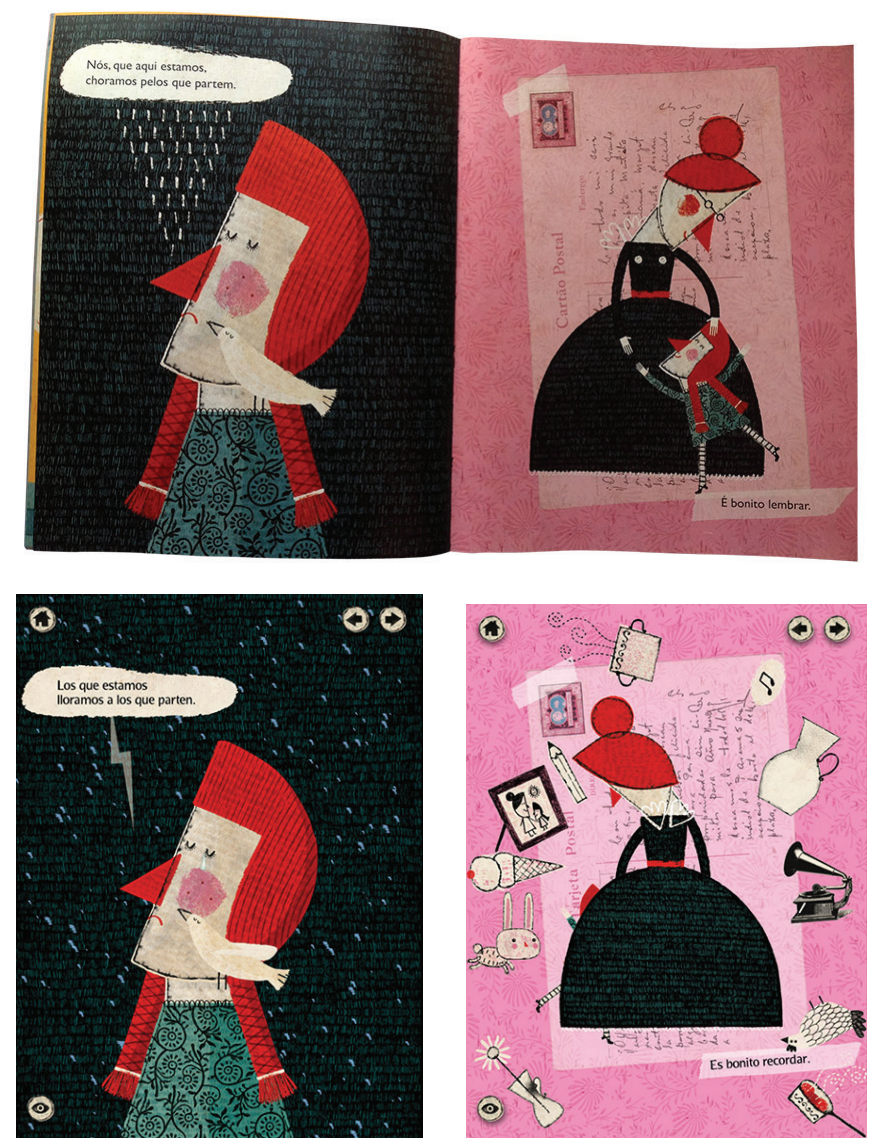

Figura 4: Cenas 5 e 6: versão impressa e versão digital (ebook interativo). Imagens capturadas pelo autor.

Neste sentido, o ebook Es así segue uma organização da multimídia baseada em telas. Isto é, uma hipermídia de forma bidimensional com elementos interativos para acionar mídias dinâmicas, interatividade e navegação entre telas.

\section{Considerações finais}

O design de um livro infantil envolve principalmente a estrutura do conteúdo no que tange a organização dos tipos de informações multimídia no contexto se sua materialidade. Nos livros tradicionais esta organização opera de acordo com critérios de relacionamento de texto e imagem de forma significativa à história. Nos livros digitais interativos, onde, devido a uma maior quantidade de mídias, a estruturação dos elementos informativos tornam-se mais complexas, é importante que haja diretrizes para organizar o conteúdo de forma efetiva para envolver o leitor à história.

O equilíbrio do conteúdo faz parte dos critérios de qualidade estipulado pelos editais do governo brasileiro para aquisição de livros infantis tradicionais. No contexto digital, em relação ao novos artefatos para leitura decorrente da proliferação das tecnologias emergentes e aquisições governamentais, faz se urgência em estabelecer critérios para organização de conteúdo agregando as mídias adicionais, tais como som e animação.

Em um livro infantil tradicional existe uma combinação de mídias, texto e imagem, no entanto, este sistema de organização não se caracteriza como uma multimídia.

De acordo com os paradigmas explorados neste estudo, a multimídia está relacionada a organização de pelo menos uma mídia estática com uma mídia dinâmica, em ambiente digital e com possibilidades interativas. O livro digital interativo de histórias infantis, partindo da organização midiática dos livros tradicionais, tornou-se uma multimídia ao adquirir suas características inerentes.

Desta maneira, o ebook interativo, sendo um aplicativo multimídia, segue o padrão de combinação de mídias utilizados em sistemas multimídia. Especificamente no ebook interativo de histórias infantis este padrão parte de uma organização decorrente dos livros tradicionais, no que tange a organização das mídias estática, texto e imagem. Podendo assim, variar entre redundância, colaboração e disjunção (LINDEN, 2011), onde cada mídia estática acompanha sua respectiva mídia dinâmica, ou seja, texto escrito com narração e imagem com animação. Tendo ainda o som como mídia integrante para ampliar o significado da narrativa.

Neste contexto, trazendo referenciais da organização de conteúdos de mídias estáticas exploradas em livros infantis tradicionais, os resultados deste estudo mostraram que a história opera como fator estruturante das mídias em ebook interativo. Desta forma, segue os princípios essenciais da composição texto-imagem de livro infantil ilustrado impresso junto aos princípios de organização da multimídia.

Como o escopo desta pesquisa não abrangeu o estudo da interatividade, é possível que este estudo seja reestruturado como roteiro de organização de mídias e interatividade na produção de livros ilustrados infantis ou como critérios de qualidade de artefatos narrativos em multimídia, tal como o ebook interativo infantil. Podendo ainda ser utilizado como critério para criação ou avaliações decorrentes de editais para aquisição de livros digitais de literatura infantil.

\section{Agradecimento}

À CAPES pelo apoio financeiro e ao Hiperlab/UFSC pela infraestrutura.

\section{Referências}

BRASIL. Ministério da Educação. Fundo Nacional de Desenvolvimento da Educação. Edital de Convocação para Inscrição de Obras de Literatura no Processo de Avaliação e seleção para o Programa Nacional Biblioteca da Escola - PNBE 2015. Disponível em: <http://www.fnde.gov.br/programas/ biblioteca-da-escola/ biblioteca-da-escola-consultas $>$. Brasília, 2014. Acesso em: 16 maio 2015.

Ministério da Educação. Programa Nacional Biblioteca da Escola - PNBE 2012 - Obras Selecionadas. 22 set. 2011. Disponível em <http://portal.mec. gov. br/index.php?option=com_docman\&task=doc 
download\&gid=13915\&Itemid=>. Acesso em 16 Maio 2015. CHAPMAN, Nigel P.; CHAPMAN, Jenny. Digital multimedia. Wiley, 2000.

CRESWELL, John W. Projeto de pesquisa: métodos qualitativos, quantitativos e misto. (tradução Magda França Lopes). 3. ed. Porto Alegre: Artmed, 2010.

COSTELLO, Vic. Multimedia Foundations. CRC Press, 2012.

CULLINAN, Bernice E. et al. Literature and the child. 8.ed. Belmont - USA: Wadsworth Cengage Learning, 2014.

FLATSCHART, Fábio. Livro Digital etc. [Digital Kobo]. Rio de Janeiro: Brasport, 2014.

JUUL, Jesper. The game, the player, the World: looking for a heart of gameness, In Level Up: Digital Games Research Conference Proceedings: Utrecht: Utrecht Universit, 2003.

LINDEN, Sophie Van der. Para ler o livro ilustrado. (tradução Dorothée de Bruchard). São Paulo: Cosac Naify, 2011.

McCLOUD, Scott. Desvendando os Quadrinhos. São Paulo: Makron Books, 1995.

RIBEIRO, Nuno. Multimédia e tecnologias interactivas. 5.ed. FCA-Editora de informática. Lisboa, 2012.

SALISBURY, Martin; STYLES, Morag. Livro infantil ilustrado: a arte da narrativa visual. São Paulo: Rosari, 2013.

SARGEANT, E. Interactive storytelling: How picture book conventions inform multimedia book app narratives. Australian Journal of Intelligent Information Processing Systems, v. 13, n. 3, p. 29-35, 2013.

SERAFINI, Frank. Reading the visual: An introduction to teaching multimodal literacy. Nova York: Teachers College Press, 2014.

SIPE, Lawrence R. Picturebooks as aesthetic objects. Literacy Teaching and Learning, v. 6, n. 1, 2001.

STICHNOTHE, Hadassah. Engineering stories? A narratological approach to children's book apps. BLFT - Nordic Journal of ChildLit Aesthetics, v. 5. Noruega, 2014.

TEIXEIRA, Deglaucy J; SOUZA, Ana Luiza C. M.; GONÇALVES, Berenice S. Interatividade e multimídia no contexto de narrativas para ebook infantil em dispositivos móveis: uma revisão sistemática. Conexão-Comunicação e Cultura, v. 13, n. 26, 2014.

TEIXEIRA, Deglaucy J. A interatividade e a narrativa no livro digital infantil: proposição de uma matriz de análise. Dissertação (Mestrado) - Programa de Pós-Graduação em Design e Expressão Gráfica, Universidade Federal de Santa Catarina. Florianópolis, 2015.

VALDIVIA, Paloma. Es así. [ebook] Cidade do México: Fondo de Cultura Económica, 2011. É assim. São Paulo: SM editora, 2012.

VAUGHAN, Tay. Multimedia: Making it work. 9.ed. Tata McGraw-Hill Education, 2014.

TOKARNIA, Mariana. Livros de escolas públicas terão versão digital em 2017. Agência Brasil. 17 Jan. 2014. Disponível em <http://memoria.ebc.com.br/ agenciabrasil/ noticia/2014-01-17/livros-de-escolas-publicas-terao-versaodigital-em-2017>. Acesso em 16 Maio 2015. 